\title{
A GIS-based model to analyze the spatial and temporal development of oil palm land use in Kuala Langat district, Malaysia
}

\begin{abstract}
In Malaysia, areas under oil palm plantations have increased dramatically since the early twentieth century and have resulted in multiple conversions of land change. This paper presents a spatial and temporal model for simulation of oil palm expansion in the Kuala Langat district, Malaysia. The model is an integration of cellular automata (CA), multicriteria evaluation (MCE), and Markov chain (MC) analysis while MCE provides transition rules of $\mathrm{CA}$ iterations and $\mathrm{MC}$ analysis assigns a transition probability to each single pixel at the time steps. Evaluation criteria consist of constraints and nine suitability factors indicating environmental and socio-economic issues of oil palm development. In the first simulation, changes of six land-cover classes were projected to the year 2008 based on transitions between 1997 and 2002. Two measures of quantity disagreement and allocation disagreement were adopted to validate model outcome. The simulation of land-cover change of the year 2020 was done based on the transition observed between 1997 and 2002 regarding the satisfactory agreement of the projection and the reference data at the first simulation. The results, based on five landscape metrics, indicated continuous spatial patterns of oil palm plantations but more fragmented spatial patterns of other land classes by the year 2020 .
\end{abstract}

Keyword: GIS; Land change modeling; Cellular automata (CA); Markov chain; Multicriteria evaluation (MCE); Quantity disagreement and allocation disagreement 